\title{
Calibrated simulation of a NZEB: The Solar Decathlon China 2018 SCUTxPoliTo Prototype
}

\author{
Ciro Lisciandrello $^{1}$, Maria Ferrara ${ }^{1}$, Alessio Messina ${ }^{1}$, Enrico Fabrizio ${ }^{1}$ \\ ${ }^{1}$ TEBE Research Group, Department of Energy, Politecnico di Torino, Torino, Italy
}

\begin{abstract}
Building model calibration is essential to minimize the gap between the designed and the real energy performance of a NZEB. This paper presents the application of an advanced optimization-based approach to calibrate a real NZEB prototype during its final design and construction phase. It relies on the synergic use of TRNSYS $^{\circledR}, \mathrm{GenOpt}^{\circledR}$ and $\mathrm{Matlab}^{\circledR}$. The reached high reliability of the model was used to properly optimize the prototype and create a daily energy planning procedure to match energy production and consumption, maximizing the final score and winning the Solar Decathlon China 2018 competition.
\end{abstract}

\section{Introduction}

In the context of the worldwide efforts to reduce energy consumptions and $\mathrm{CO}_{2}$ emissions of the building sector, the concept of NZEB has increased its popularity and building simulation has emerged as the most popular tool to predict in details the energy performance of different NZEB design alternatives and support decision making within the design process (Ferrara, 2019). Furthermore, the availability of a reliable energy model, which reflects the behavior and the performance of the building after construction, has been proved to be effective in supporting also the building operation phase, thus contributing to reduce the "performance gap" (Wilde, 2014) often occurring between the predicted performance at the design stage and the actual performance after construction. To do so, it is necessary to calibrate the energy model based on monitored data, in order to perform the required "tuning" of the model to fit its behavior to the actual building behavior. (Monetti, 2016).

It is known that there are several methods for building model calibration, from manual calibration to graphicalbased calibration methods, from calibration based on special tests and analysis procedures to automated techniques for calibration, based on analytical and mathematical approaches. Since the first introduction of this classification (Clarke, 1993), many studies were published about applications and advancements related to one or the other method. In the last few years, the increasing effectiveness of simulation-based optimization methods (SBOM) tailored for the NZEB design process (Ferrara et al., 2018) has led to increasing interest in studying the application of the same methods to building model calibration. When compared to manual methods, such optimization-based calibration method presents some advantages. In fact, they do not rely on the experience of the user to carry on the optimization but on a solid mathematical structure. Moreover, the computational time is highly reduced at the same level of exploration of the viable solutions (Yang, 2016). In order that these advantages are fully exploited, the users have to be really precise in selecting input parameters and optimization method. The choice could be guided through a Sensitivity Analysis (SA). The SA will actively explore the hyperspace of possible solutions and rank the parameters accordingly to their influence on the final outcome (Tian, 2013).

\section{Context and Objectives of the work}

This study has been developed within the Solar Decathlon China 2018 competition, a worldwide engineering and architecture challenge in which student teams have to design, build and operate a NZEB.

The competition evaluates the project based on measured and juried parameters: the measured ones need to be maintained in a certain range in order to lower as much as possible the energy consumption while optimizing the stability and the efficiency of the systems. Such level of precision has to rely on a solid simulation that is capable to predict the behaviour of the envelope and consequently simulate the performance of systems in details. This need constitutes the main objective of this work, that is the creation of a reliable simulation model to justify and verify many design alternatives and to check if they match the requests of the contest. This offers a unique occasion to advance in research concerning model calibration. In fact, the integrated process from design to construction and operation and the easiness of collecting a large amount of data constitutes a fertile base for research that are hard to find in other contexts.

Therefore, the approach used to reach the main objective is composed of the following steps:

- Set up a simulation-based optimization framework able to calibrate the performance of a NZEB building;

- Carry on a complete SA based on an optimized Morris Method to improve the efficiency of the framework;

- Test the method on a real NZEB prototype;

- Evaluate the impact of the use of this method within the context of the Solar Decathlon competition. 


\section{The LONGPLAN prototype}

The NZEB prototype, whose name is LONG PLAN (Fig.1), is based on the concept of the narrow house, to face the problem of high-density city urbanization and land consumption. It has two floors, the net area is about $143 \mathrm{~m}^{2}$, it has a modular steel structure with 12 prefabricated modules.

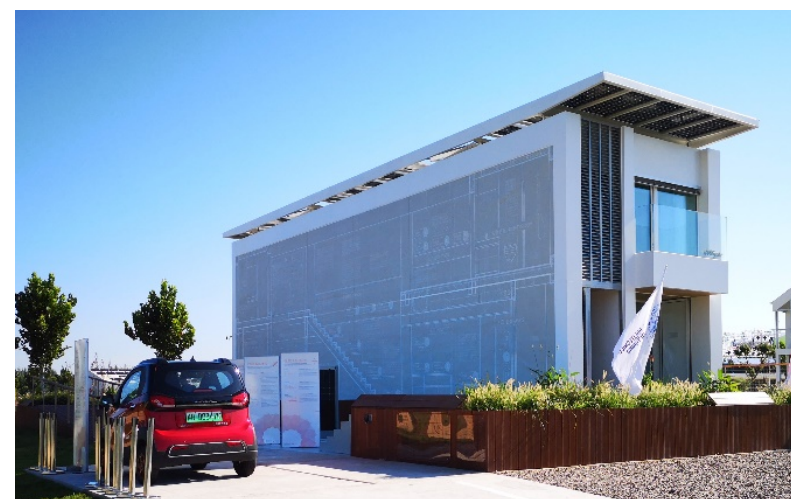

Figure 1: Picture of the LONG PLAN house

The building is a two-storey house that can be divided into three main volumes, also called "belts":

- Implemented Wall Belt: The west-side external wall of which the internal part contains all the distribution pipes for hot water, coolant, DHW and all the electrical and electronic connection, to contain the use of space, and to make the maintenance easier;

- Service Belt: A narrow "slice" of the house, composed of all the services and systems. Here lay the stairs, the 3 bathrooms, the mechanical room, the aquaponic system and the kitchen appliances;

- Living Belt: This section is composed by the 4 conditioned zones: living room, kitchen and the two bedrooms. There is one corridor for each floor too and a central patio, with an automated roof windows, to improve passive strategies such as the chimney effect.

Transparent envelope $\left(\mathrm{U}_{\mathrm{w}}\right.$ ranging from $0.8 \mathrm{~W} / \mathrm{m}^{2} \mathrm{~K}$ to $1.2 \mathrm{~W} / \mathrm{m}^{2} \mathrm{~K}$ ) is only on north and south facades (shortest sides), plus two skylights near the staircase, because the longest walls will be adjacent to the other houses. The opaque envelope is composed of OSB (Oriented Strain Board) panels, VIP (Vacuum Insulated Panels), phenolic insulation, water barrier, vapor barrier (roof and walls: $\mathrm{U}=0.095 \mathrm{~W} / \mathrm{m}^{2} \mathrm{~K}$; ground slab: $\mathrm{U}=0.129 \mathrm{~W} / \mathrm{m}^{2} \mathrm{~K}$ ). The east and west facades are heavily insulated, to simulate the performance of the adjacent house, avoiding extra gains, and a ventilated façade is added to limit solar gains. In the city of Dezhou, Shandong, China, thermal loads were estimated to be $16 \mathrm{~kW}$ for cooling and $9 \mathrm{~kW}$ for heating. To cover these loads, the HVAC system (Fig. 2) of the prototype was developed focusing on the modularity and feasibility of the project. All the technologies applied for the systems are market-available. The cooling system is composed of a Variable Refrigerant Volume (VRV-Daikin $\left.{ }^{\circledR}\right)$ Heat Pump connected with four internal units with enhanced dehumidification capability. The heating system is composed of a 4-loop capillary heating system that is fed by the same external heat pump through a high efficiency heat exchanger. The four loops are independent, the mats are pre-casted inside the concrete of the floor in the main conditioned rooms.

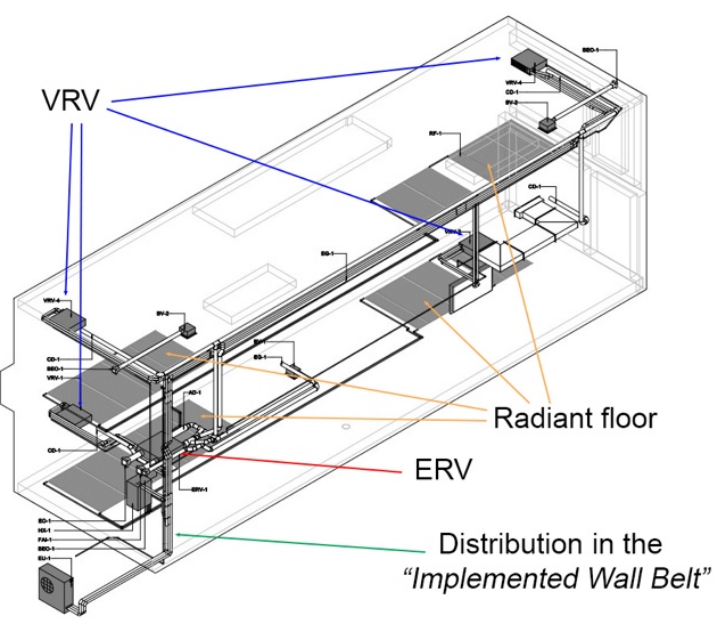

Figure 2: 3-D Schematic of the prototype HVAC system

There is a recycling system for the grey water and condensate from the HVAC system, which saves around half of a typical water consumption, and uses the purified water to different purposes: feed the plants, toilet flush, sprinkler system, rain garden.

The ventilation system was designed to reduce the $\mathrm{CO}_{2}$ and $\mathrm{PM}_{2.5}$ concentration in the inside air. An Energy Recovery Ventilator was designed to provide a fresh air flow of $350 \mathrm{~m}^{3} / \mathrm{h}$. The outdoor air is firstly filtered in a coarse filter and then in a finer one, obtaining a filtering efficiency to the PM2.5>99\%. The air then passes through a counter flow heat exchanger in which it exchanges sensible energy with the exhaust air to reduce the conditioning load on the inside. The air is sent directly inside the living belt, in the 4 conditioned rooms, while the extraction is located in the corridor of the first floor and next to the top of the aquaponic system on the second floor (this position was chosen to highly reduce the amount of humidity near the green-wall). The flow path is ensured by the normal air leakage of the internal doors without increasing the pressure drops considerably.

On the roof, $11 \mathrm{~kW}_{\mathrm{p}}$ of high-efficiency PV panels are installed on a steel structure. The electricity generated is supposed to be used in the building and to charge the battery of an electric vehicle. There are also $6 \mathrm{~m}^{2}$ of solar thermal panels to produce domestic hot water, combined with an electrical resistance to increase availability and temperature control.

\section{Methods}

The procedure for the calibration set-up is composed of the following steps (Fig. 3):

- Measurement campaign to gather data on the weather conditions and the internal temperatures of thermal zones; 
- Creation of the Building Energy Model (BEM), with implementation of the measured weather data into the model;

- Sensitivity analysis on the BEM input parameters to determine the calibration parameters;

- BEM handling to create the coupling with the optimization software;

- Iterative Optimization to calibrate the model accordingly with the progress of the construction site:

- "free floating" calibration, which calibrates the envelope parameters based on measured and simulated indoor air temperatures when the building is running in free-floating (without HVAC system);

- "final calibration", which considers both envelope and system parameters as it is performed when the building is running with its HVAC system;

- Data Post Processing with possibility of active intervention on the final construction of the building prototype.

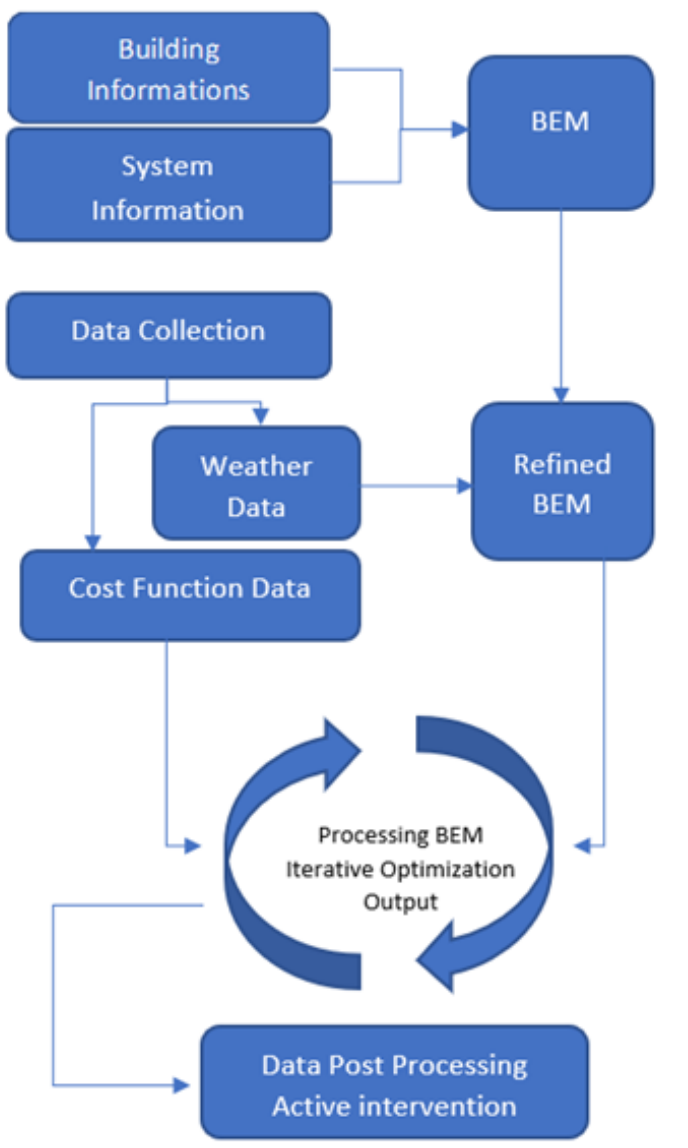

Figure 3: Optimization-based calibration framework

\section{Measurements: data collection}

As mentioned, a large set of measured data is necessary to calibrate a building simulation model. The measurement campaign was organized in parallel with the last phase of construction of the building.

The first dataset is related to weather data, which were collected by means of:
- Davis Vantage Pro2 weather station;

- Delta Ohm HD2102 Solar Flux Datalogger;

- LP Pyra02 Pyranometer.

The position of the sensors was set to reduce the effect of nearby building or environment and maintain the sensors safe from the building site operation (Royapoor et al., 2015). The weather station was placed on the north-west corner, with the wind probe at the height of 3 meter (first floor). The Pyranometer was placed on top of the workers stall to reduce the horizontal interaction with other structures and avoid any kind of shading (allowed $<5^{\circ}$ on the horizontal).

Another dataset was collected regarding internal temperatures of thermal zones, to proceed with the socalled temperature calibration (Royapoor et al., 2015). The analysis of the temperature evolution can highlight the accuracy of the simulation and is easily gatherable. Measurements were organized dividing the thermometers (HOBO U23-001) according to their timestep (2 minutesTherm. A and 5 minutes - Therm. B). Therm. A were placed in couples in the main thermal zones, while The Therm. A, used for the actual measurements, were placed at the geometrical centre of the zone at a height of $1.5 \mathrm{~m}$ as shown in Fig. 4. Therm. B were placed at the top of walls in the connection zones and were used to check the temperature fluctuation between zones.

Figure 4: Placement of temperature sensors

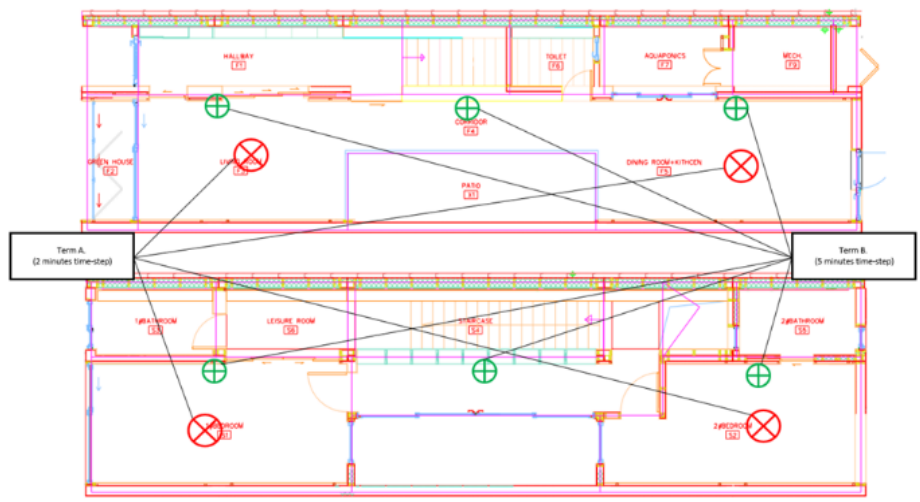

At the beginning of the prototype construction phase, which lasted a couple of weeks, the activities focused on the measurement architecture, the sensors placement and model updating with the actual prototype configuration. This led to carry out measurements for 3 days, allowing a level 4 calibration, based on short-term monitoring (Fabrizio et al., 2015).

\section{The simulation model}

The simulation model was created in TRNSYS ${ }^{\circledR}$. In order to increase the model level of detail while maintaining the calculation manageable, the overall modelling was split into the Building Model (BM), describing the building envelope behaviour and the related energy needs, and the HVAC System Model (SM).

The core Type for the BM simulation is the Type-56; it allows a detailed description of the envelope and the 
different zones, simulated through a nodal configuration. The zoning considered 16 zones, of which 4 (the ones in bold in Table 1) are directly conditioned. This allows direct control of the conditioned spaces even if they are part of a bigger open space (Raftery et al., 2011): having smaller thermal zones implies a higher control on the ventilation flow path and higher precision on the temperature and humidity values in that particular part of the prototype. These characteristics are fundamental to reduce the averaging effect of the temperature in other zones and limit the mismatch between the simulated and measured values.

Table 1: Zones of the model (ref Fig.2)

\begin{tabular}{|c|c|c|}
\hline Code & Room/Zone & Vol $\left[\mathbf{m}^{\mathbf{3}}\right]$ \\
\hline F1 & Hallway & 20.7 \\
\hline F2 & Greenhouse & 9.6 \\
\hline F3 & Living Room & $\mathbf{3 9 . 7}$ \\
\hline F4 & Corridor & 20.3 \\
\hline F5 & D.R.+Kitchen & $\mathbf{4 9 . 4}$ \\
\hline F6 & Bathroom 1 & 6.9 \\
\hline F7 & Aquaponics & 13.4 \\
\hline F8 & Mechanical Room & 10.6 \\
\hline S1 & Bedroom 1 & $\mathbf{4 9 . 3}$ \\
\hline S2 & Bedroom 2 & $\mathbf{4 4 . 3}$ \\
\hline S3 & Bathroom 2 & 12.0 \\
\hline S4 & Staircase & 81.1 \\
\hline S5 & Bathroom 3 & 12.0 \\
\hline S6 & Leisure Room & 14.6 \\
\hline X1 & Patio & 61.6 \\
\hline X2 & Cabinet & 3.0 \\
\hline
\end{tabular}

The SM includes the cooling, the ventilation and the heating system, although the latter was switch off during the contest simulation. In addition to this, the simulation includes the management system, and graphical and numerical output.

The ventilation model considers the infiltration from openings and air flows based on pressure and temperature differences between the different zones. It was created through the TRNSYS coupling with CONTAM Multizone Air Flow, which also allowed simulating the chimney effect.

The Cooling system was simulated using 4 different standard split types. The part load power was defined through an equation type, which determines the energy needed to reach the setpoint based on the room temperatures at each timestep.

This equation was developed from the COP table in part load provided by the producer through a polylinear regression (Fig. 4). The resulting goodness-of-fit is as follows:

- R-square: 0.9964

- Adjusted R-square: 0.9961

- RMSE: 0.1329

The external unit type reads the part load as the sum of all the power used by the internal machines and the outdoor temperature from the weather file and give the COP as an output to evaluate the electrical energy consumption.

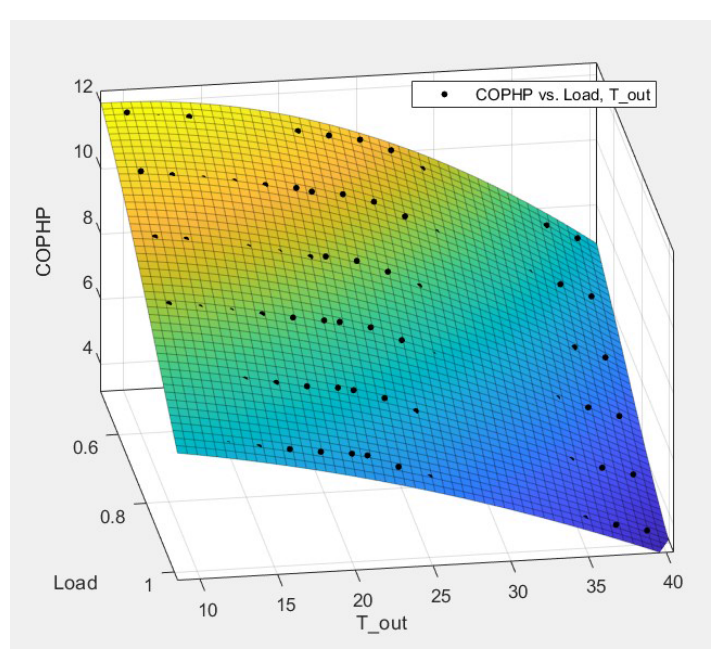

Figure 4: Model of the system COP in part load

\section{Sensitivity analysis}

The described modelling assumptions determine a list of 302 simulation input parameters, but only some of them can be actively used for calibration due to their source or the use done in the simulation, as highlighted by $\mathrm{R}$. Enriquez at al. (2013). Moreover, the number of calibration parameters should be limited to ensure acceptable computational time. A first user selection can be performed(Fabriek, 2013), but then it is necessary to ensure that the selected parameters are those having the highest impact on the simulation outcome. This can be done through sensitivity analysis.

Several Sensitivity Analysis methods could be applied to a model giving different information about the input parameters (Nguyen et al., 2015). The Morris method was selected as a compromise between the so-called local (high level of information about inputs) and global methods (no information about inputs). This procedure shares some characteristics from both local and global methods (Saltelli et al., 2015), of which the advantages are as follows:

- Provides the influence sorting of the parameters;

- Does not depend on properties and does not require linearity assumption (difficult to make using building energy models);

- The hyperspace can be explored evenly without defining parameters' probability density functions in advance;

- Graphical interpretation of the results;

- Reduced computational time;

- Relatively easy implementation.

The Morris Method (Morris, 1991) works using "trajectories": from a first step in the hypercube of possible values the coordinates move variating only one parameter at each step. It relies on the evaluation of a Sensitivity Index several times for every parameter. Such Index is called Elementary Effect and is defined as

$$
E E_{i}\left(\underline{X}^{j}\right)=\frac{Y\left(X_{1}^{j}, \ldots, X_{i-1}^{j}, X_{i}^{j}+\Delta, X_{i-1}^{j}, \ldots, X_{k}^{j}\right)-Y\left(\underline{X}^{j}\right)}{\Delta}
$$


where $X i$ is one of the k parameters composing a system and $Y$ represents the system's output before and after the variation of the $i^{\text {th }}$ parameter of the quantity $\Delta$. Once the Elementary effect is computed for each of the $r$ trajectories $j$, the mean value $\mu_{i}$ and the standard deviation $\sigma_{i}$ are evaluated to allow the sorting of the parameters.

The Morris method was implemented through a MATLAB code after the Optimized Latin Hypercube Sampling was performed, based on the so-called Campolongo's procedure (Campolongo et al., 2007), to obtain a set of exhaustive trajectories to explore the solution space and limit the risk of leaving unexplored large parts of the parameter space. This led to determine 10 different trajectories.

The parameters were set as variable in the TRNSYS simulation input files with a batch file calling a function to write the value of the parameter accordingly to the trajectory at that step. The list of 29 selected input parameters and the range for their variation is reported in Table 2. In order to ensure their weight is the same within the analysis, 4 steps were defined for each variation range. When the reported unit is "\%", it means that the variation of that parameter is based on a percentage value that modifies the initial design values of parameters.

Table 2: Input parameters for sensitivity analysis

\begin{tabular}{|c|c|c|c|c|}
\hline Parameter & Min & Max & Unit & $\#$ \\
\hline $\begin{array}{l}\text { ERV Sensible } \\
\text { Effectiveness }\end{array}$ & -0.1 & 0.1 & $\%$ & 1 \\
\hline $\begin{array}{c}\text { Internal Convective Heat } \\
\text { Transfer Coefficient }\end{array}$ & 5 & 9 & $\mathrm{~kJ} / \mathrm{hm}^{2} \mathrm{~K}$ & 2 \\
\hline $\begin{array}{l}\text { External Convective Heat } \\
\text { Transfer Coefficient }\end{array}$ & 55 & 75 & $\mathrm{~kJ} / \mathrm{hm}^{2} \mathrm{~K}$ & 3 \\
\hline $\begin{array}{l}\text { Internal Convective Heat } \\
\text { Transfer Coefficient W }\end{array}$ & 5 & 9 & $\mathrm{~kJ} / \mathrm{hm}^{2} \mathrm{~K}$ & 4 \\
\hline $\begin{array}{l}\text { External Convective Heat } \\
\text { Transfer Coefficient_W }\end{array}$ & 55 & 75 & $\mathrm{~kJ} / \mathrm{hm}^{2} \mathrm{~K}$ & 5 \\
\hline Infiltration flow rate F3 & -0.1 & 0.1 & $\%$ & 6 \\
\hline Infiltration flow rate F5 & -0.1 & 0.1 & $\%$ & 7 \\
\hline Infiltration flow rate $\mathrm{S} 1$ & -0.1 & 0.1 & $\%$ & 8 \\
\hline Infiltration flow rate S2 & -0.1 & 0.1 & $\%$ & 9 \\
\hline Air coupling zones F1-S4 & -0.1 & 0.1 & $\%$ & 10 \\
\hline Air coupling zones F7-S4 & -0.1 & 0.1 & $\%$ & 11 \\
\hline Shading Factor Horizontal & 0 & 0.1 & - & 12 \\
\hline Air flow natural ventil. & 0 & 700 & $\mathrm{~m}^{3} / \mathrm{h}$ & 13 \\
\hline $\begin{array}{c}\text { U-Value Frame Windows } \\
\text { type } \# 1\end{array}$ & -0.1 & 0.1 & $\%$ & 14 \\
\hline $\begin{array}{l}\text { Area frame/glass } \\
\text { Windows type \#1 }\end{array}$ & 0.1 & 0.2 & $\%$ & 15 \\
\hline $\begin{array}{l}\text { U-Value Frame Windows } \\
\text { type \#2 }\end{array}$ & -0.1 & 0.1 & $\%$ & 16 \\
\hline $\begin{array}{l}\text { Area frame/glass } \\
\text { Windows type \#2 }\end{array}$ & 0.1 & 0.2 & $\%$ & 17 \\
\hline $\begin{array}{c}\text { U-Value Frame Windows } \\
\text { type \#3 }\end{array}$ & -0.1 & 0.1 & $\%$ & 18 \\
\hline $\begin{array}{l}\text { Area frame/glass } \\
\text { Windows type \#3 }\end{array}$ & 0.1 & 0.2 & $\%$ & 19 \\
\hline $\begin{array}{c}\text { Zones Capacitance } \\
\text { F3/Volume }\end{array}$ & 35 & 55 & $\mathrm{~kJ} / \mathrm{K}$ & 20 \\
\hline $\begin{array}{c}\text { Zones Capacitance } \\
\text { F5/Volume }\end{array}$ & 50 & 70 & $\mathrm{~kJ} / \mathrm{K}$ & 21 \\
\hline
\end{tabular}

\begin{tabular}{|c|c|c|c|c|}
\hline $\begin{array}{c}\text { Zones Capacitance } \\
\text { S1/Volume }\end{array}$ & 50 & 70 & $\mathrm{~kJ} / \mathrm{K}$ & 22 \\
\hline $\begin{array}{c}\text { Zones Capacitance } \\
\text { S2/Volume }\end{array}$ & 45 & 60 & $\mathrm{~kJ} / \mathrm{K}$ & 23 \\
\hline Phenolic Conductivity & -0.05 & 0.05 & $\%$ & 24 \\
\hline VIP Thermal resistance & -0.05 & 0.05 & $\%$ & 25 \\
\hline $\begin{array}{c}\text { Approx. average ground } \\
\text { surface temp. }\end{array}$ & 293 & 303 & $\mathrm{~K}$ & 26 \\
\hline $\begin{array}{c}\text { Absorbance Frame } \\
\text { Windows type \#1 }\end{array}$ & -0.1 & 0.1 & $\%$ & 27 \\
\hline $\begin{array}{c}\text { Absorbance Frame } \\
\text { Windows type \#2 }\end{array}$ & -0.1 & 0.1 & $\%$ & 28 \\
\hline $\begin{array}{c}\text { Absorbance Frame } \\
\text { Windows type \#3 }\end{array}$ & -0.1 & 0.1 & $\%$ & 29 \\
\hline
\end{tabular}

\section{Simulation-based optimization for calibration}

As mentioned, the proposed approach involves the coupling of a Building Energy Modelling Software, TRNSYS ${ }^{\circledR}$, with an Optimization program, GenOpt ${ }^{\circledR}$. To perform such optimization-based calibration, an optimization cost function should be set, based on the difference between the measured and the simulated data set. In this work, the optimization objective function was set according to the standards for considering a calibration validated; this was done in order to achieve within the same operation both the calibration and its validation. The standard used for reference is the ASHRAE Guideline 14 (ASHRAE, 2002). The validation of the calibration is based mainly on two statistical indices ( $\mathrm{S}$ - simulated data; M - measured data):

- Normalized Mean Bias Error (MBE)

$$
\operatorname{NMBE}(\%)=\frac{\Sigma_{\text {Period }}(S-M)_{\text {interval }}}{\Sigma_{\text {Period }} M_{\text {interval }}} \cdot 100 \%
$$

- Coefficient of Variation of the Root Mean Square Error (Cv(RMSE))

$$
\begin{gathered}
C v\left(R M S E_{\text {Period }}\right)=\frac{R M S E_{\text {Period }}}{A_{\text {Period }}} \cdot 100 \\
R M S E_{\text {Period }}=\sqrt{\frac{\Sigma(S-M)_{\text {interval }}^{2}}{N_{\text {interval }}}} \\
A_{\text {period }}=\frac{\Sigma_{\text {Period }} M_{\text {interval }}}{N_{\text {intervl }}}
\end{gathered}
$$

The threshold limits for both NMBE and Cv(RMSE) are reported in Table 3.

Table 3: Calibration thresholds (from ASHRAE 2002)

\begin{tabular}{|c|c|c|}
\hline \multirow{2}{*}{$\begin{array}{c}\text { Statistical } \\
\text { indices }\end{array}$} & \multicolumn{2}{|c|}{ ASHRAE Guideline 14 } \\
\cline { 2 - 3 } & $\begin{array}{c}\text { Monthly } \\
\text { Calibration }\end{array}$ & $\begin{array}{c}\text { Hourly } \\
\text { Calibration }\end{array}$ \\
\hline NMBE (\%) & \pm 5 & \pm 10 \\
\hline Cv(RMSE) $(\%)$ & 15 & 30 \\
\hline
\end{tabular}

Therefore, the cost function that the optimization process has to minimize can be expressed as follows

$$
C F=N M B E \cdot 0.5+C v(R M S E) \cdot 0.5
$$

where the same statistical weight is assigned to both the NMBE and the $\mathrm{Cv}$ (RMSE).

For the optimization in GenOpt, a hybrid global optimization algorithm was selected (Wetter, 2011). This algorithm starts with a Particle Swarm Optimization (PSO) on a mesh, for a number of generations $n_{G}$ defined by the user. Then, it initializes the Generalized Pattern 
Search (GPS) algorithm for the continuous independent variables, while discrete variables are fixed at the value of the particle with the lowest cost function value. Thus, the hybrid algorithm combines the global features of the PSO algorithm with the provable convergence properties of the GPS algorithm, thus ensuring higher accuracy while limiting the risk of being attracted by local minima.

Being the algorithm already pre-loaded in the GenOpt scripts, it only needs some simple commands to perform the optimization. It is required to write the GenOpt configuration file, containing indication about the simulation program to call, and the command file, where the optimization parameters are defined and the and algorithm settings are reported.

Moreover, the simulation should be prepared to ensure that the TRNSYS input file is ready to be called iteratively by GenOpt and evaluate the cost function according to the calibration objectives.

First of all, the weather file should be built with the collected data and connected with the needed type(s). The selected format is, as previously said, the Type109Userdefined. The data handling was performed through and Excel file in order to increase the length of the weather data accordingly to the length of the simulation.

Then the temperatures measured in the zones have to be read by the simulation to evaluate the deviation of the calculated data from the real ones. The format used is the simple Type9a: this type allows to create a simple tab with interpolating features and user-defined time interval.

Then, at each simulation run, a MATLAB script called within the TRNSYS simulation allows evaluating the cost function on hourly-averaged values provided by a TRNSYS output file. The script handles the temperatures, measured and simulated ones, of all the 4 different zones separately, and proceeds with the calculation of the cost function using the worst condition (the data set that are on average on the biggest distance).

As a last step, the coupling between TRNSYS and GenOpt should be finalized by editing the TRNSYS input files. The editing entails creating two template files where GenOpt is able to write different values of optimization parameters driven by the algorithm, thus creating different simulation input files at each iteration.

\section{Results}

\section{Results of the sensitivity analysis}

The sensitivity analysis was launched with the aim of creating two sets of parameters to be used for the two different steps of calibration: one regarding the envelope calibrated simulation, here called "free floating" calibration, and the other for the final calibration including also the system performance. The resulting set of selected parameters, in relation with the two indices $\mu$ and $\sigma$ (indicating mean and standard deviation of elementary effects (1) over trajectories) are shown in Fig. 5. The orange points represent the set of 7 parameters used for the free-floating calibration, violet points represent the set of 10 parameters used for final calibration, while the red points are the discarded parameters. The selected parameters are also reported in Table 4. Refer to Table 2 for description of parameters.

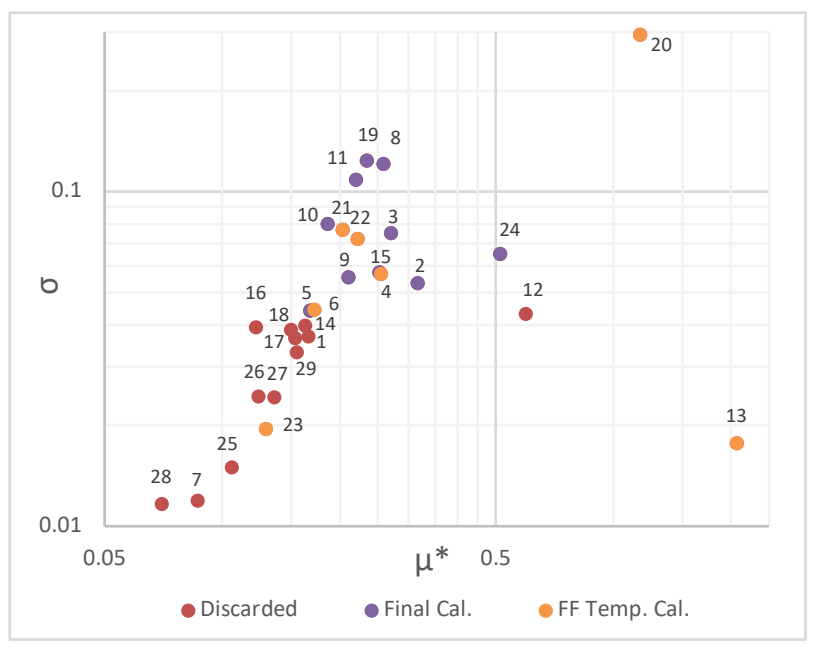

Figure 5: Parameter selected from sensitivity analysis

Table 4: Set of parameters selected for calibration

\begin{tabular}{|c|c|c|c|c|c|}
\hline \multicolumn{2}{|c|}{ Free Floating Calibration } & \multicolumn{3}{c|}{ Final Calibration } \\
\hline$\#$ & $\mu^{*}[\mathbf{k W h}]$ & $\sigma[\mathbf{k W h}]$ & $\#$ & $\mu^{*}[\mathbf{k W h}]$ & $\sigma[\mathbf{k W h}]$ \\
\hline $\mathbf{1 3}$ & 2.0583 & 0.0177 & $\mathbf{6}$ & 0.1672 & 0.0441 \\
\hline $\mathbf{1 5}$ & 0.2539 & 0.0568 & $\mathbf{1 9}$ & 0.2335 & 0.1240 \\
\hline $\mathbf{2 1}$ & 0.2020 & 0.0773 & $\mathbf{8}$ & 0.2568 & 0.1211 \\
\hline $\mathbf{2 2}$ & 0.2207 & 0.0726 & $\mathbf{2 4}$ & 0.5109 & 0.0652 \\
\hline $\mathbf{2 0}$ & 1.1619 & 0.2946 & $\mathbf{3}$ & 0.2683 & 0.0752 \\
\hline $\mathbf{2 3}$ & 0.1288 & 0.0196 & $\mathbf{4}$ & 0.2509 & 0.0576 \\
\hline $\mathbf{5}$ & 0.1711 & 0.0444 & $\mathbf{2}$ & 0.3137 & 0.0534 \\
\hline & & & $\mathbf{1 1}$ & 0.2181 & 0.1089 \\
\hline & & & $\mathbf{9}$ & 0.2095 & 0.0557 \\
\hline & & & $\mathbf{1 0}$ & 0.1851 & 0.0803 \\
\hline
\end{tabular}

\section{Free Floating Calibration}

For the free-floating calibration, the simulation was rearranged to speed up the runs removing the components related to systems that, due to the building site operation, were not used. The resulting reduced simulation maintains the infiltration handlers, the air coupling simulation in CONTAM. Within the optimization process, the simulation was iteratively launched with the following characteristics:

- Simulation Start time: $3144 \mathrm{hr}$

- Simulation Stop time $3216 \mathrm{hr}$

- Simulation timestep: $1 \mathrm{~min}$

- Weather file: User defined

The minimization of the cost function (eq. (6)) during the optimization process is shown in Figure 5.

The resulting optimal set of parameter values is reported in Table 5, while the goodness of fit according to the ASHRAE thresholds is reported in Table 6. As shown, the model results to be well calibrated.

The graphs in Figure 6 report the simulated temperature of the worst zone (blue) with respect to the measured one 
(red) and the outdoor conditions (green). The first graph in Fig. 7 shows the conditions pre-calibration. In the second graph, reporting the conditions after the freefloating calibration, it is shown that the deviation during daytime is almost totally reduced and differences in the behaviour during nigh time appear just in presence of sudden change in outdoor conditions.

Table 5: Optimized parameters values-free float. Calib.

\begin{tabular}{|c|c|c|c|c|}
\hline \multicolumn{5}{|c|}{ Free Floating Calibration } \\
\hline \# & Parameter & Description & Value & Unit \\
\hline 13 & AC od & Air Flow Nat. Vent. & 25 & $\mathrm{~m}^{3} / \mathrm{h}$ \\
\hline 15 & Rat fr_fac & Ratio Frame/Glass & 0.2 & $\%$ \\
\hline 21 & Cap_f5 & \multirow{4}{*}{$\begin{array}{c}\text { Capacitance thermal } \\
\text { zone }\end{array}$} & 51 & \multirow{4}{*}{$\mathrm{kJ} / \mathrm{K}$} \\
\hline 22 & Cap_s1 & & 69 & \\
\hline 20 & Cap $\mathrm{f3}$ & & 69 & \\
\hline 23 & Cap s2 & & 58 & \\
\hline 5 & HW_out & $\begin{array}{l}\text { Outdoor conv. heat } \\
\text { transfer wind. }\end{array}$ & 59 & $\begin{array}{c}\mathrm{kJ} / \mathrm{h} \\
\mathrm{m}^{2} \\
\mathrm{~K}\end{array}$ \\
\hline
\end{tabular}

Table 6: Result validation - free floating calibration

\begin{tabular}{|l|c|c|c|}
\hline & Value & Threshold & Validated \\
\hline Cost function & +2.62 & - & - \\
\hline NMBE (\%) & +4.27 & \pm 10 & $\mathrm{x}$ \\
\hline Cv(RMSE) & +4.88 & 30 & $\mathrm{x}$ \\
\hline
\end{tabular}

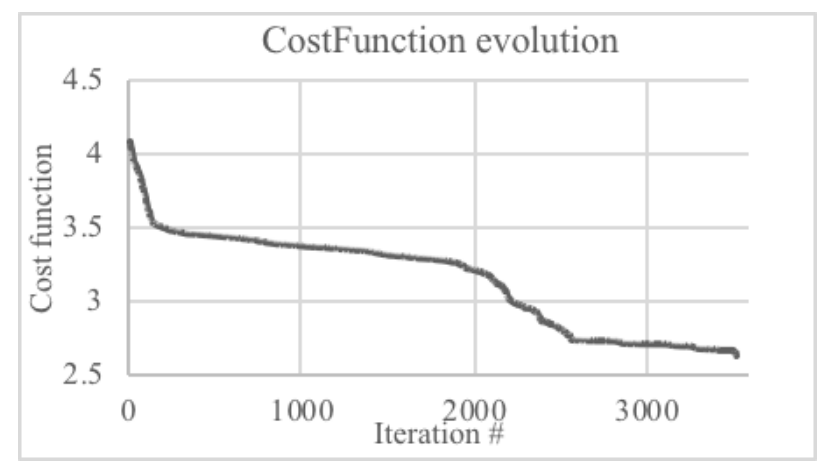

Figure 5: Cost function minimization

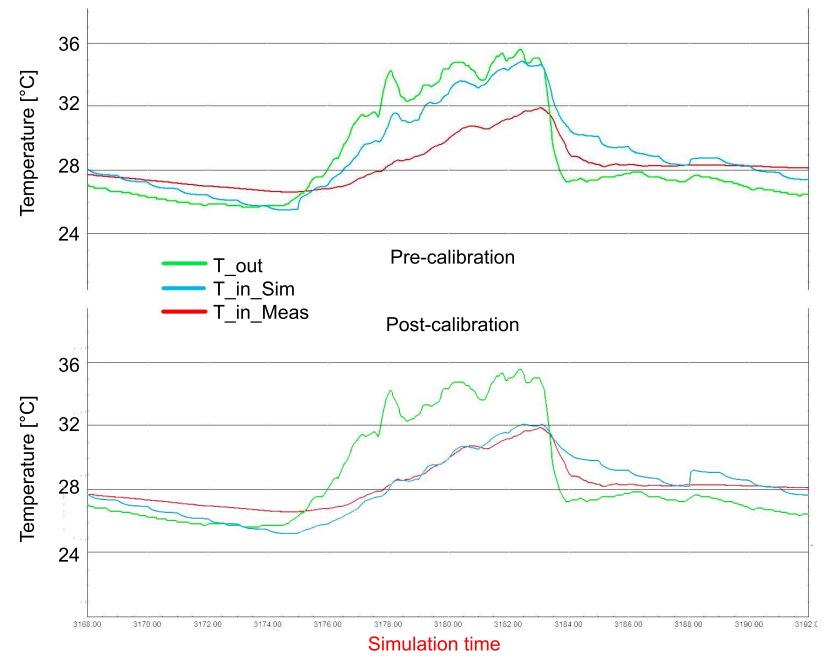

Figure 6: Zone temperatures pre and post calibration

\section{Final Calibration}

Because the final objective of calibration is to have a reliable model in summer period, during the contest, the heating system were removed, according to the principle of keeping the model as simple as possible to reduce computational time. Due to the building site's operational status it was possible to collect usable data only for night time and, based on the previously calibrated model in free-floating, proceed with an evidence-based calibration of the remaining parameters during the pre-competitions test days.

The finalization of the prototype construction was done in strict relation with simulation. The final calibration, based on the first set of optimization-based calibrated parameters, was performed by trial and error. The fact that the most influencing parameters had already been identified through the performed sensitivity analysis facilitated the process of manually varying the values of parameters to match the behaviour of the systems. At the end of the process, an increased level of precision was reached, with a simulation stable enough to consider the simulation calibrated and use it for short term planning during the competition. Figure 8 reports measured versus simulated data in the last pre-contest simulation. The goodness of the final calibration is reported in Table 7.

Table 7: Result validation - final calibration

\begin{tabular}{|c|c|c|c|}
\hline \multirow{2}{*}{ Final } & $\begin{array}{c}\text { Values } \\
(\%)\end{array}$ & \multirow{2}{*}{ Threshold } & Validated \\
\cline { 2 - 3 } & Zone S 1 & & \\
\hline NMBE & 6.39 & \pm 10 & $x$ \\
\hline CV(RMSE) & 9.13 & 30 & $x$ \\
\hline
\end{tabular}

\section{Conclusion}

The proposed approach resulted effective in leading the presented building prototype to win the Solar Decathlon China 2018 competition and may be replicated to optimize the role of simulation in a real building construction and management process. The test of the building behaviour by means of the calibrated model was useful to prevent unexpected errors in the contest measurements.

The optimization-aided calibration offered a good range of available codes for performing the final simulation, giving the opportunity to pick the one that better suits the simulation and to tailor it to the specifics of the wanted calibration. The results give a substantial help to the monitoring and planning system and have shown the flexibility of the calibration procedure in reshaping itself according to the building site and operational needs.

The two-stage calibration approach (only envelope first, then envelope + HVAC systems), adopted mainly for practical reasons, has resulted to be effective in reaching good results while maintaining the model physically realistic and manageable. We believe this approach can be useful to be replicated on other buildings, provided a sensitivity analysis is performed to select a proper set of calibration parameters. 


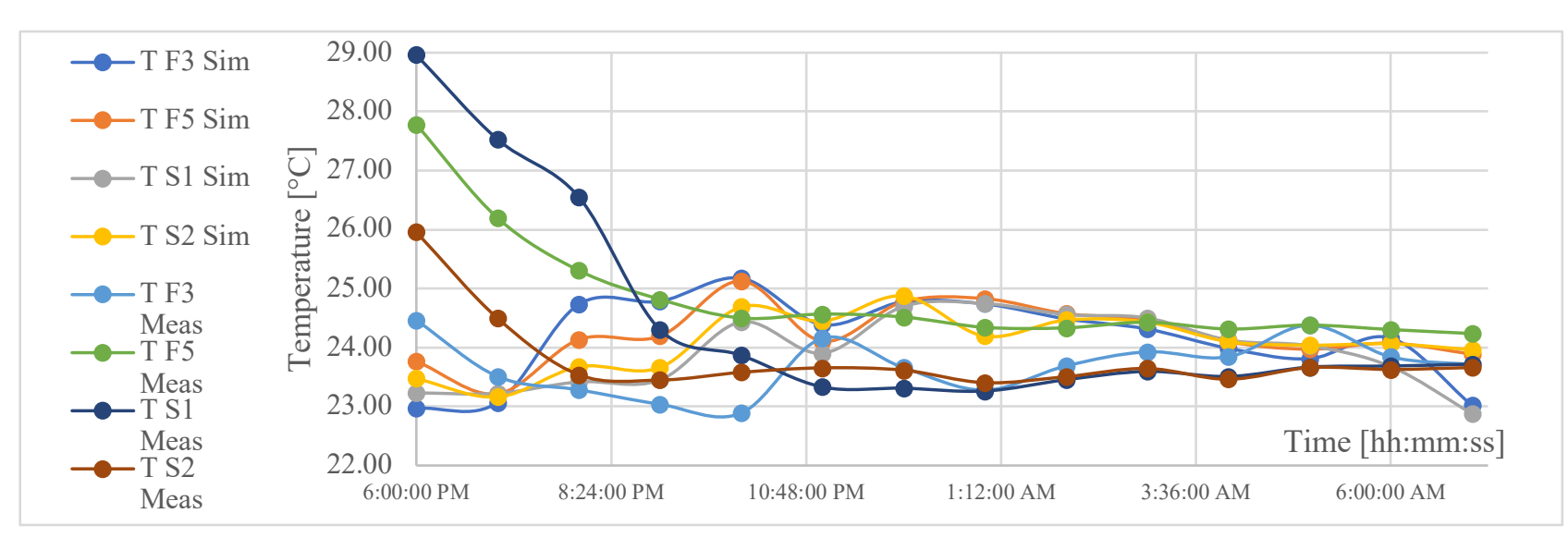

Figure 8: Measured versus simulated data after final calibration

\section{Acknowledgement}

This work has been performed as part of the activities of the team SCUT-POLITO (South China University of Technology, Guangzhou, China - Politecnico di Torino, Turin, Italy), winner of the Solar Decathlon China 2018 contest ( http://www.sdchina2017-scutpolito.com).

The contribution of all the students composing the team from Italy and China is acknowledged, supervised by the followings:

SCUT professors: Sun Yimin, Wang Jing, Xiao Yiqiang, Xu Haohao, Zhang Yufeng, Zhong Guanqiu.

PoliTo professors: Mauro Berta (Scientific coordinator, DAD), Michele Bonino (DAD), Orio De Paoli (DAD), Enrico Fabrizio (DENERG), Marco Filippi (DENERG), Francesca Frassoldati (DAD), Matteo Robiglio (DAD), Valentina Serra (DENERG), Edoardo Bruno (DAD).

LINKS-SiTI research group: Romano Borchiellini (DENERG), Sergio Olivero, Paolo Lazzeroni, Federico Stirano.

\section{References}

ASHRAE Guideline 14 (2002). Measurement of Energy Demand and Savings.

Campolongo, F., Cariboni, J., Saltelli, A. (2007) An effective screening design for sensitivity analysis of large models. Environmental Modelling \& Software 22, 1509-1518.

Clarke, J.A.; Strachan, P.; Pernot, C. (1993). An approach to the calibration of building energy simulation models. ASHRAE Transactions 99, 917-927.

Enríquez, R., Jiménez, M.J., Heras, M. (2012) Analysis of a Solar Office Building at the South of Spain Through Simulation Model Calibration, Energy Procedia 30, 580-589.

Fabriek, P.H. (2013) Sensitivity analysis of residential building simulations: model choice for specific applications and critical parameters. Master thesis, TU Delft.
Fabrizio, E., Monetti, V. (2015) Methodologies and Advancements in the Calibration of Building Energy Models. Energies 8, 2548-2574.

Ferrara, M, Fabrizio, E. (2017) Cost optimal nZEBs in future climate scenarios. Energy Procedia 122, 877882.

Ferrara, M., Sirombo, E., Fabrizio, E. (2018). Automated optimization for the integrated design process: the energy, thermal and visual comfort nexus. Energy and Buildings 168, 413-427.

Morris, M. D. (1991) Factorial Sampling Plans for Preliminary Computational Experiments. Technometrics 33, 161-174.

Mustafaraj, G., Marini, D., Costa, A., Keane, M. (2014) Model calibration for building energy efficiency simulation. Applied Energy 130, 72-85

Nguyen, A., Reiter, S. (2015) A performance comparison of sensitivity analysis methods for building energy models. Building simulation 8, 651-664.

Raftery, P., Keane, M., O’Donnell, J. (2011) Calibrating whole building energy models: An evidence-based methodology. Energy and Buildings 43, 2356-2364.

Royapoor, M., Roskilly, T. (2015) Building model calibration using energy and environmental data, Energy and buildings 94, 109-120.

Saltelli, A., Ratto, M., Campolongo, F., Andres, T., Tarantola, S. (2008) Global Sensitivity Analysis. The Primer. John Wiley and Sons. Chichester (UK).

Tian, W. (2013). A review of sensitivity analysis methods in building energy analysis. Renewable and Sustainable Energy Reviews 20, 411-419.

Wetter, M. (2011). GenOpt Generic Optimization Program User Manual, v3.1.0.

Wilde, P. (2014) The gap between predicted and measured energy performance of buildings: A framework for investigation. Automation in Construction 41, 40-49.

Yang, T., Pan, Y., Mao, J., Wang, Y., Huang, Z. (2016). An automated optimization method for calibrating building energy simulation models with measured data: Orientation and a case study. Applied Energy 179, 1220-1231. 